\title{
Extruded Rods with <001> Axial Texture of Polycrystalline Ni-Mn-Ga Alloys
}

\author{
H. Morawiec ${ }^{1, a}$, J. Lelątko ${ }^{1, b}$, T. Goryczka ${ }^{1, c}$, K. Prusik ${ }^{1, d}$ \\ St. Piechota ${ }^{2, e}$, D. Stróź ${ }^{1, f}$ \\ ${ }^{1}$ Institute of Materials Science - University of Silesia, Katowice, Poland \\ ${ }^{2}$ Institute of Physics - PAS, Warszawa, Poland \\ aHenryk.Morawiec@us.edu.pl, 'Jozef.Lelatko@us.edu.pl, 'Tomasz.Goryczka@us.edu.pl, \\ 'Krystian.Prusik@us.edu.pl, êspiech@ifpan.edu.pl, 'Danuta.Stroz@us.edu.pl
}

Keywords: FSMA, extrusion, texture, Ni-Mn-Ga.

\begin{abstract}
The Ni-Mn-Ga alloys extruded at high temperature with a relatively large reduction rate were the subject of the studies. The microscopic observations of the transient zone in the extruded rods revealed rotation of the columnar grains in the ingot along the rod axis - giving the preferred $<001>$ orientations. Comparison of the texture, magnetization and magneto-crystalline anisotropy constant for samples cut out from the columnar grain zone and these cut from the extruded rods was carried out for two alloys which differ in chemical composition and $M_{s}$ temperature. Both alloys have the $5 \mathrm{M}$ martensitic structure at room temperature. The samples cut out of the ingot and the extruded rods have shown the axial <001> orientation, similar magnetization curves and magnetocrystalline anisotropy constant $\mathrm{K}_{\mathrm{u}}=1.5-1.6 \mathrm{~J} / \mathrm{m}^{3} \cdot 10^{5}$.
\end{abstract}

\section{Introduction}

The main theoretical principles for selection ferromagnetic shape memory alloys based on Heusler compounds are generally known and experimentally proved for single crystals of $\mathrm{Ni}-\mathrm{Mn}-\mathrm{Ga}$ alloys $[1,2]$. The summary of the latest achievements in this field has been given in $[3,4]$. Extension of these results to polycrystalline materials would significantly increase the application capabilities of this class of materials. It is also understood that the magnetic-field-induced-strain (MFIS) of the polycrystalline alloys is remarkably smaller than that of single crystals because of the randomly oriented grains and twin variants in martensite. One of important factor which controls the MFIS effect is the magneto-crystalline anisotropy of the martensite with $c / a<1$.

A crystallographic texture of the polycrystalline alloy can meaningly improve this effect because the preferred orientation is the $\langle 001\rangle$ direction which is the easy magnetization direction. The trials of obtaining the textured polycrystalline Ni-Mn-Ga alloys include the directional solidification [5], melt spun ribbon processing [6] and directional deformation [7-10].

The plastic deformation of these alloys done by compression at high temperature was studied by Böhm et al. [7]. They observed essential lowering the flow stress at $1000^{\circ} \mathrm{C}$ compared to $800^{\circ} \mathrm{C}$. The microstructure of the martensite after deformation showed the presence of twins. The possibilities of deformation carried out by hot rolling of small ingots of Ni-Mn-Ga alloys placed in an iron cylinder were shown by Besseghini et al. [8]. It was stated, that the deformation had a beneficial effects such as homogeneity of the alloys and possibility to close pores and holes in the as cast material. More detailed studies of the deformation by hot rolling were published by Bin et al. [9]. The authors, while comparing the diffraction patterns before and after hot rolling stated increase of the (202), (400) and (323) diffraction peaks and concluded the presence of the (400) texture. The direct texture determination of the hot rolled Ni-Mn-Ga alloys by pole figures projection using the x-ray and EBSD methods was described in [10]. The aim of this work was to introduce into the studied alloys the axial $<001\rangle$ texture by rod extrusion process and to determine the effect of the privileged orientation on the magnetocrystalline anisotropy constant. 


\section{Experimental procedure}

The studied two batches of polycrystalline alloys were prepared by melting in an induction furnace under argon atmosphere using $99.99 \%$ pure elements. The chemical composition was determined by the EDS method. The $\mathrm{M}_{\mathrm{s}}$ temperatures, structure and characteristic parameters of the studied alloys are given in Table 1 . The round ingots of $20 \mathrm{~mm}$ diameter were homogenized at $1100^{\circ} \mathrm{C}$ for 2 hours and extruded into rods of $10 \mathrm{~mm}$ diameter with the reduction rate of $75 \%$.

Table 1: Chemical composition and characteristic parameters for the studied Ni-Mn-Ga alloys.

\begin{tabular}{|c|c|c|c|c|c|c|c|c|c|c|}
\hline $\begin{array}{c}\text { Allo } \\
\mathrm{y}\end{array}$ & $\begin{array}{l}\mathrm{Ni} \\
\text { [at\%] }\end{array}$ & $\begin{array}{l}\mathrm{Mn} \\
\text { [at\%] }\end{array}$ & $\begin{array}{c}\mathrm{Ga} \\
{[\mathrm{at} \%]}\end{array}$ & $\begin{array}{l}\mathrm{M}_{\mathrm{s}} \\
{[\mathrm{K}]}\end{array}$ & $\begin{array}{c}\text { Structure of } \\
\text { martensite }\end{array}$ & Texture & $\underset{\left[\mathrm{J} / \mathrm{m}^{3} \times 10^{5}\right]}{\mathrm{K}_{\mathrm{u}}}$ & $\begin{array}{c}\tau_{m a g=} K_{u} / \gamma_{0} \\
{\left[\mathrm{~J} / \mathrm{m}^{3} \times 10^{5}\right]}\end{array}$ & $\begin{array}{r}\tau_{\text {mag }} \\
{[\mathrm{MPa}]}\end{array}$ & $\begin{array}{c}\tau_{y} \\
{[\mathrm{MPa}]}\end{array}$ \\
\hline \multirow[t]{2}{*}{3} & \multirow[t]{2}{*}{49.13} & \multirow[t]{2}{*}{27.48} & \multirow[t]{2}{*}{23.39} & \multirow[t]{2}{*}{328} & \multirow{2}{*}{$\begin{array}{l}\text { Five- } \\
\text { layer } \\
(5 \mathrm{M})\end{array}$} & $\begin{array}{l}\text { Columnar } \\
\text { oriented } \\
\text { grains }\end{array}$ & 1.6 & 12.92 & 2.56 & 10 \\
\hline & & & & & & $\begin{array}{l}\text { Axial } \\
\text { texture } \\
\text { of rods }\end{array}$ & 1.62 & 13.02 & 2.58 & 10 \\
\hline \multirow[t]{2}{*}{6} & \multirow[t]{2}{*}{51.5} & \multirow[t]{2}{*}{28.8} & \multirow[t]{2}{*}{19.8} & \multirow[t]{2}{*}{366} & \multirow{2}{*}{$\begin{array}{l}\text { Five- } \\
\text { layer } \\
(5 \mathrm{M})\end{array}$} & $\begin{array}{l}\text { Columnar } \\
\text { oriented } \\
\text { grains }\end{array}$ & 1.53 & 12.44 & 2.47 & 25 \\
\hline & & & & & & $\begin{array}{c}\text { Axial } \\
\text { texture of } \\
\text { rods }\end{array}$ & 1.76 & 14.19 & 2.81 & 2.5 \\
\hline
\end{tabular}

The die was heated to be sure that the extrusion process was carried out in the B2 phase state. The specimens were cut in a rectangular shape along the $\langle 001\rangle$ direction of the columnar grains from the round shape ingots and extruded rods. The texture was studied by EBSD using (001) and (110) pole figures. The Kikuchi patterns are generated from a $50 \mathrm{~nm}$ deep layer, which requires a careful surface preparation. A final polishing step using colloidal diamond suspension was used for this purpose. The EBSD measurements were carried out with the use of the scanning electron microscope (JEOL JSM 6480) equipped with Nordlys II camera supported by a computer with the HKL Channel 5 system. In order to collect the grain orientation from large surfaces the experiments were carried out at magnification of $100 \mathrm{x}$ and the grid step size of $4 \mu \mathrm{m}$. Every orientation map consisted of 4 mapping jobs.

\section{Results and discussion}

The annealing of the ingots at $1100^{\circ} \mathrm{C}$ caused the radial growth of the columnar grain perpendicular to the ingot axis. This produced the preferred $\langle 001\rangle$ orientation along the radius of the ingot. Figure 1 shows the macroscopic view of the transient ingot zone, the scheme of extrusion and the part of transient ingot-rod. The extrusion cause the rotation of the $<001>$ oriented grains to the rod axis direction. In this way the grains along the extrusion axes obtain the [001] orientation.
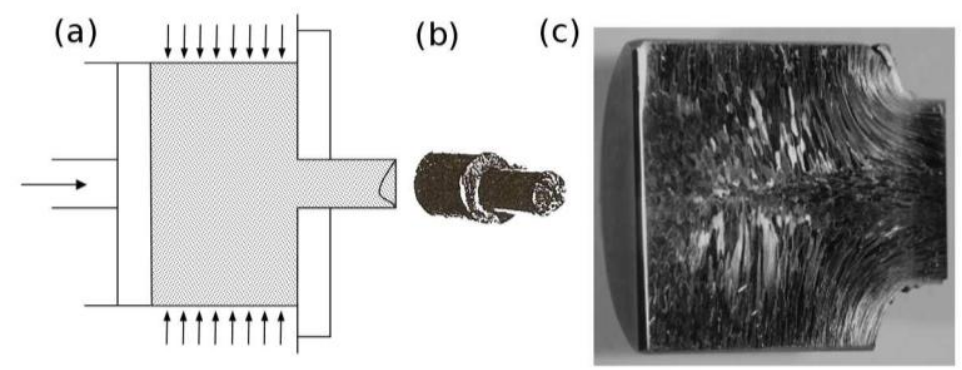

Fig. 1: Scheme of extrusion $(a)$ part of transient ingot-rod $(b)$ and macrostructure of the transient zone $(c)$ 
The microstructure of the rods is characterized by large elongated grains as shown in Fig. 2 . The martensitic plates with high twin density in alloy 3 were observed (Fig. 3) within the grains.

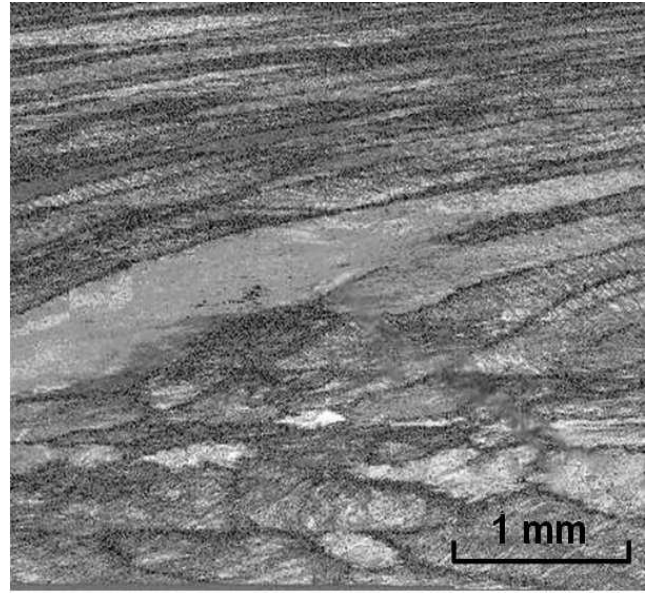

Fig. 2: Elongated grains in the extruded rod

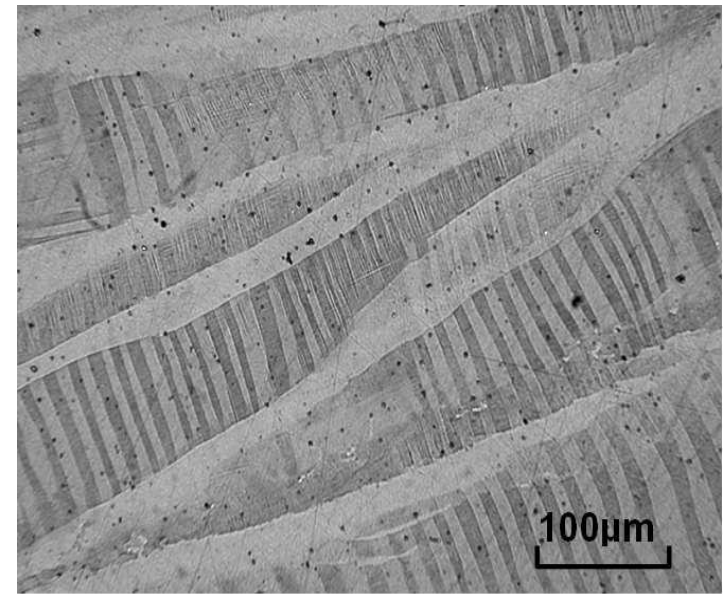

Fig. 3: Microstructure of the martensitic elongated grains in the rod

The TEM studies revealed that the studied alloys show the five-layered 5M structure of the martensite. Fig. 4. shows the microstructure and electron diffraction pattern of 5M martensite for alloy 3 .
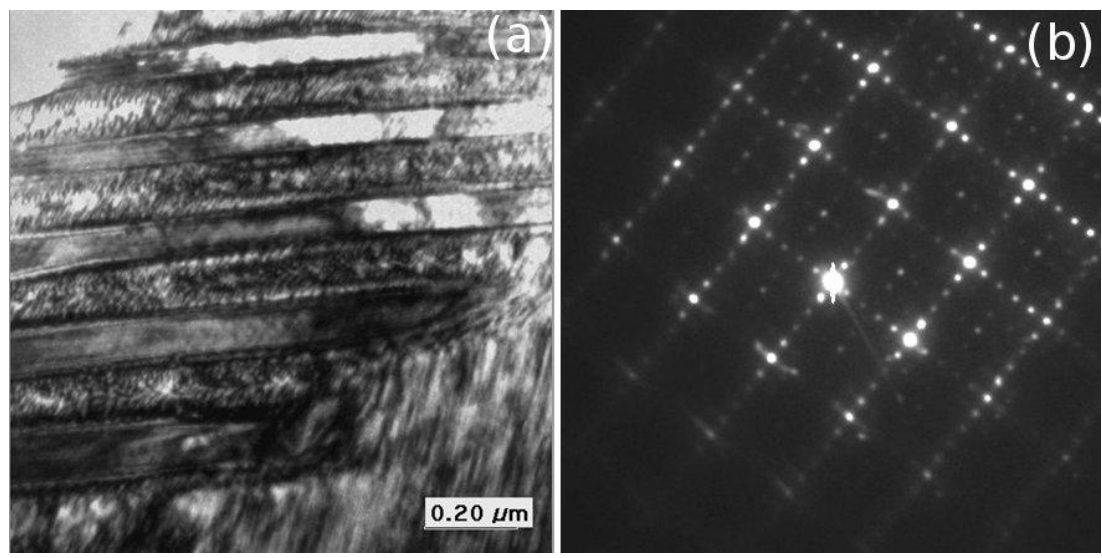

Fig. 4: Morphology of martensite (a) and diffraction pattern of five-layered structure in alloy 3 (b)

The aim of the studies was to compare the texture, magnetization and magnetocrystalline anisotropy constant for samples containing columnar grain zone and these cut from the extruded rods. The pole figures obtained from the transversal cross section for a sample cut out of the columnar grains of alloy 3 are shown in Fig. 5. The pole figures confirm the $\langle 001\rangle$ texture. The distribution of the orientations in the pole figures show that the specimen is a strongly textured polycrystalline material. 

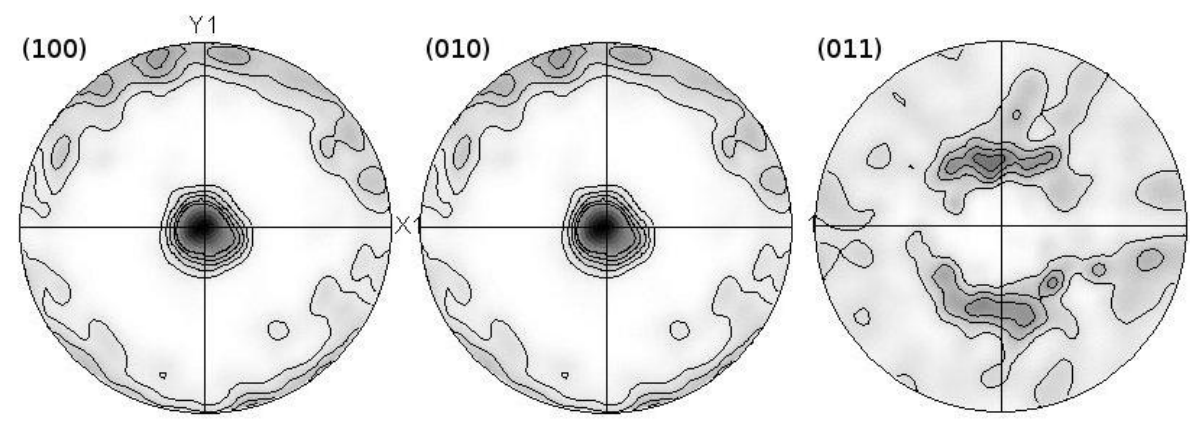

Fig. 5: EBSD pole figures of the columnar grains of the alloy 3 specimen

The pole figures of the extruded rod from the alloy 3 taken from the longitudinal cross section (Fig. 6) contain the scattered data of the grains oriented about the $\langle 001\rangle$ direction. Computer processing of the scattered data allows to contour the pole figures and thus reveals the preferred orientation. The interpretation of the texture in the tetragonal martensite with $c / a=0.94$ was based on the assumption that within $2 \%$ of accuracy it may be carried out using the standard projection for the cubic system.
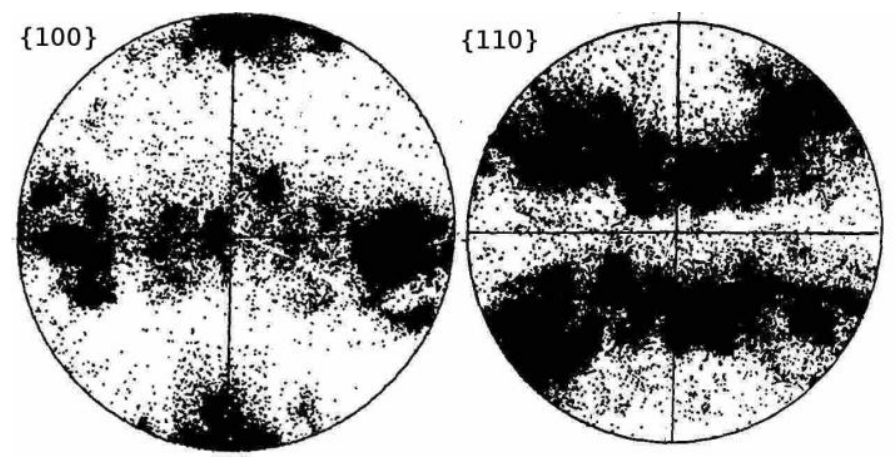

Fig. 6: EBSD pole figures with scattered data of the axial texture in the extruded rod of alloy 3 specimen

The magnetization curves for both specimens with columnar grain texture and the extruded rod are shown in Fig. 7 and Fig. 8, respectively. The latter one shows 3 curves: the $c$ curve for the longitudinal direction which corresponds to the <001> direction and the $a$ and $b$ are related to the transverse direction of the rectangular shape of the sample. The magnetic field $H$ corresponding to the saturation of magnetization varied between 0.9 and $1.4 \mathrm{~T}$ and the values of the magnetization saturation $M$ changed from 50 to $65 \mathrm{emu} / \mathrm{g}$. The macroscopic model of the magnetic-field-induced-strain assumes that the magnetic shear stress $\tau_{m a g}$ must exceed the yield stress for the twin boundary motion $\tau_{y}$. This condition has been stated generally [11-13] as:

$\tau_{\text {mag }}=\frac{K_{u}}{\gamma_{0}}>\tau_{y}$

where: $K_{u}$ is the uniaxial magnetocrystalline anisotropy constant and $\gamma_{0}$ is shear strain involved in the process. The value of $K_{u}$ is calculated from magnetization measurements basing on the relation:

$\mu_{0} M H=2 K_{u}$

where $M$ is the saturation magnetization and $H$ is the value of the magnetic field related to $M$. The shear strain $\gamma_{0}$ is calculated from the tetragonal lattice distortion of $5 \mathrm{M}$ martensite. 
The used relation is as follows:

$\gamma_{0}=\left[1-(c / a)^{2}\right] /(1-c / a)$

for the five-layered martensite $\gamma_{0}=0.12$. It is well known that for the field-induced twin boundary motion to occur, application of the magnetic field must result in the mechanical shear stress on the atoms on the twin plane so that this plane moves into the unstable variant.

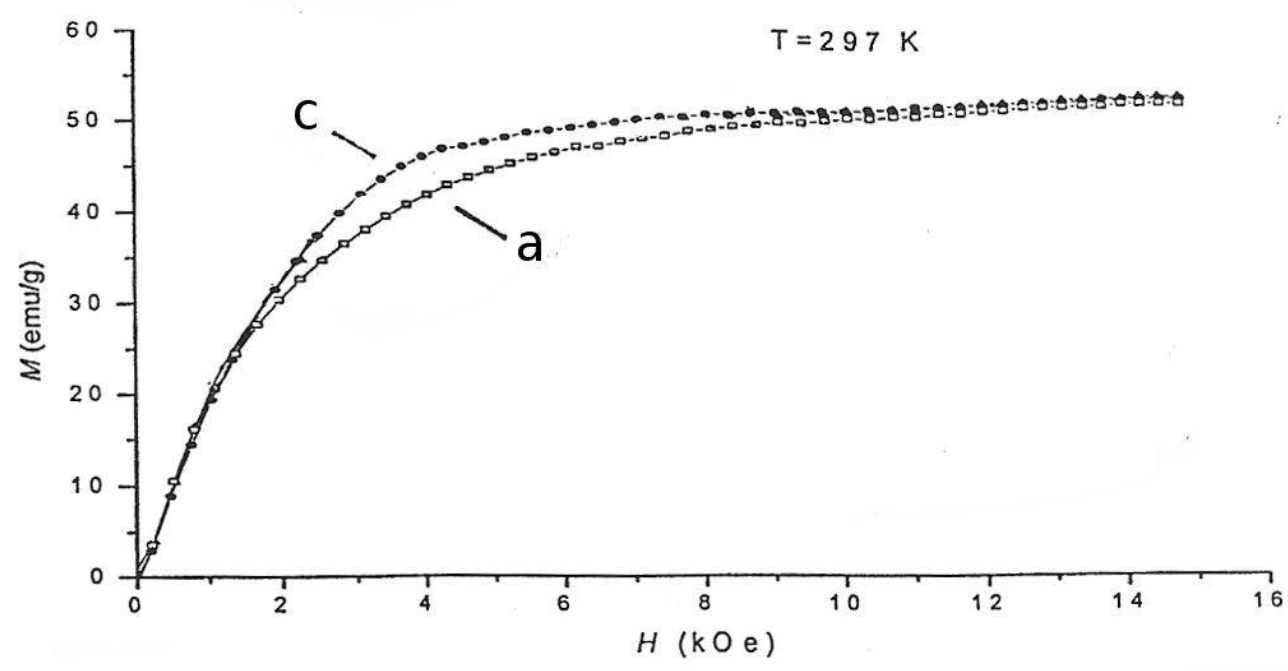

Fig. 7: Magnetization curves for columnar grain oriented alloy 3 specimen, along the $c$ and $a$ axis

To lower the twin boundary motion yield stress the mechanical training [14] was carried out on the rectangular samples along three axes with different stress. The obtained results are satisfying only for the samples of the extruded rods of alloy 6 . The obtained value is $\tau_{y}=2.5 \mathrm{MPa}$. All the calculated and measured $\tau_{\mathrm{y}}, K_{u}$ and $\tau_{\mathrm{y}}$ which characterize the ferromagnetic shape memory alloys are given in Table 1.

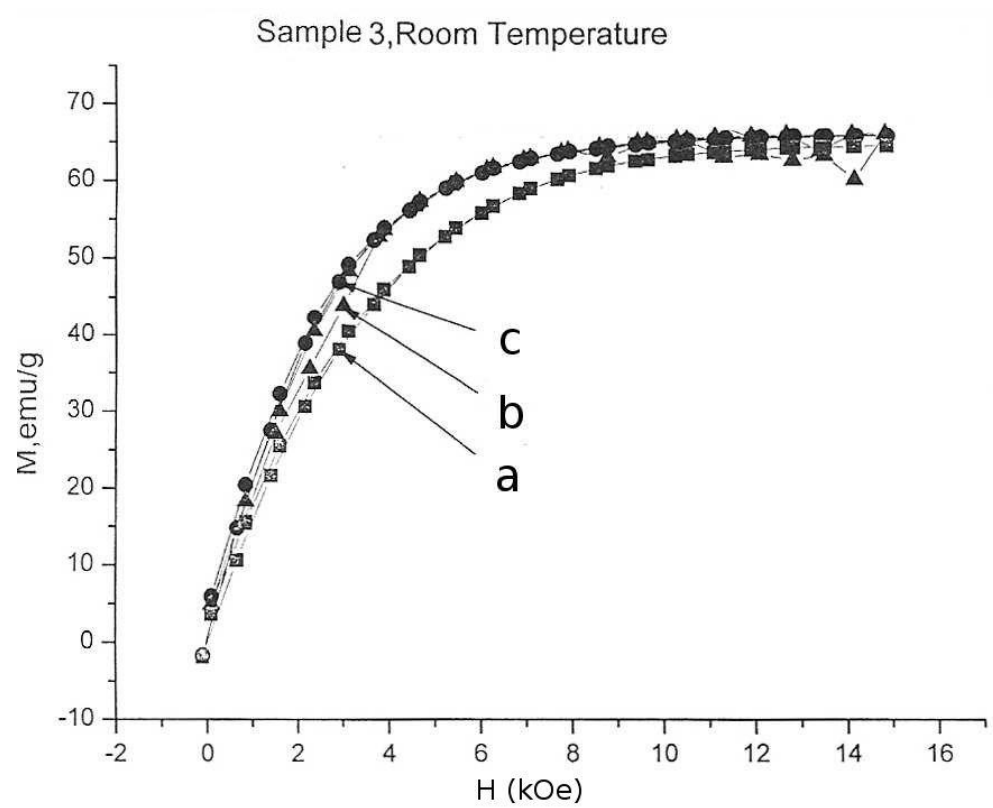

Fig. 8: Magnetization curves for axial textured rod alloy 3 specimen: transverse $(a, b)$ and longitudinal direction $(c)$ 


\section{Conclusions}

- Polycrystalline Ni-Mn-Ga alloys with relatively strong <001> texture axis may be obtained by rod extrusion,

- The calculated magnetic shear stress values and magnetocrystalline anisotropy constant are comparable to the single crystal data [11-13],

- The lowering of the twin yield stress by mechanical training was not successful for all studied alloys.

\section{Acknowledgements}

This work was financially supported by the Ministry of Science and High Education (project PBZ-KBN-115/T08/2006).

\section{References}

[1] A.A. Likhachev, K. Ullakko: Phys. Lett. A 275 (2000), p. 142

[2] A. Sozinov, A.A. Likhachev, N. Lanska, K. Ullakko: Appl. Phys Lett. 80 (2002), p. 1746

[3] Advances in Shape Memory Materials - Ferromagnetic Shape memory alloys, ed. by V.A. Chernenko, Trans Tech Publications, 2008

[4] Ferromagnetic Shape Memory Alloys, ed. by Ll. Mañosa, Trans Tech Publications, 2008

[5] M. Pötschke, U. Gaitzsch, S. Roth, B. Rellinghause, L. Schultz, J. Magn. Magn. Mater. 316 (2007), p. 383

[6] Z.H. Liu, X.X. Zhang, M. Zhang, X.F. Dai, H.N. Hu, J.L. Chen, G.H. Wu: Phys. Lett. A 329 (2004), p. 214

[7] A. Böhm, S. Roth, G. Naumann, W.G. Drossel, R. Neugebauer: Mater. Sci. Eng. A 481-482 (2008), p. 266

[8] S. Besseghini, E. Villa, F. Passaretti, M. Pini, F. Bonfanti: Mat. Sci. Eng. A 378 (2004), 415

[9] L. Bin, W. Hua-Bin, L. Yan, L. Ji-Xuan, W.H. Lei: Trans. Nonferrous Met. Soc. China 16 (2006), p. 843

[10]H. Morawiec, T. Goryczka, A. Drdzeń, J. Lelątko, K. Prusik, Solid State Phenomena, 154 (2009), p. 133

[11]R.C. O’Handley, D.I. Paul, S.M. Allen, M. Richard, J. Feuchtwanger, B. Peterson, R. Techapiesancharoenkij, M. Barandiarán, P. Lázpita, Mater. Sci. Eng. A 438-440 (2006), p. 445

[12]T. Kakeshita, T. Fukuda, Eur. Phys. J. Special Topic 158 (2008), p. 73

[13]N. Okamoto, T. Fukuda, T. Kakeshita, T. Takeuchi, Mater. Sci. Eng. A 438-440 (2006), p. 948

[14] U. Gaitzsch, M. Pötschke, S. Roth, B. Rellinghaus, L. Schultz, Scr. Mat. 5 (2007), p. 493 